
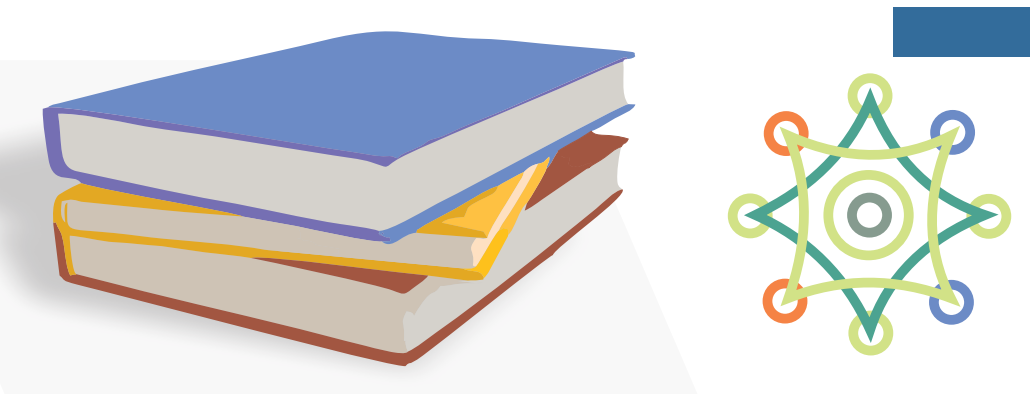

RE V IS TA
PRACTICUM libros

Número 6(1), Enero-Junio, 2021

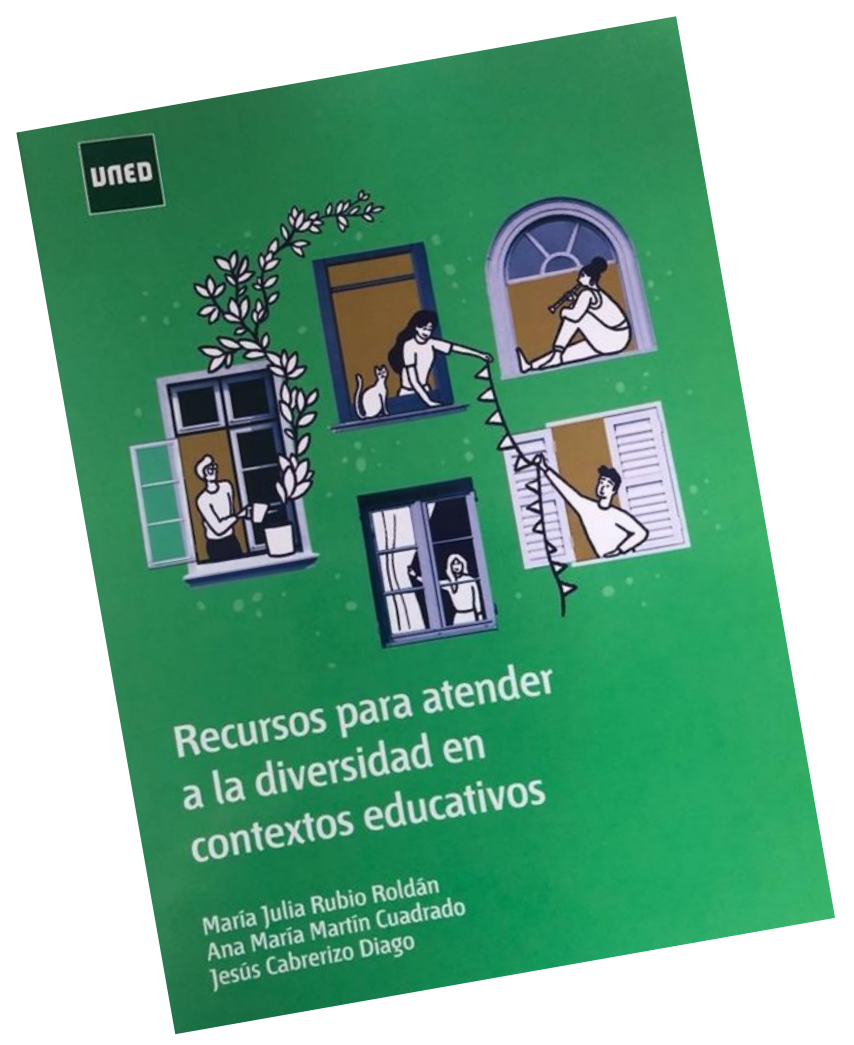

“... atender a la diversidad supone una forma de interactuar y de trabajar con todos los alumnos de un centro con independencia del programa al que estén adscritos." (p.9)

En las últimas décadas, los avances legislativos a nivel educativo, los cambios sociales y el esfuerzo por visibilizar la diversidad y atender a las nuevas realidades presentes en las comunidades educativas, hace que un tema tan trabajado en los centros, como es la atención a la diversidad, se vuelva de plena actualidad en este momento. Es precisamente esta realidad compleja de la que hablamos, la que nos permite presentar este documento como

\section{Recursos para atender a la diversidad \\ en contextos educativos}

\section{Rubio Roldán, M.J., Martín Cuadrado, A. M. y Cabre- rizo Diago, J. (Coords.)}

Editorial: Universidad Nacional de Educación a Distancia

Año de edición: 2020

Ciudad: Madrid (España)

ISBN: 978-84-362-7620-6

№ de Edición: octubre 2020

№ de páginas: 284

Idioma: Español

un referente para responder ante situaciones a las que se enfrentan diariamente los profesionales de la enseñanza.

El escrito que tenemos ante nosotros se estructura en seis capítulos, con un contenido de creciente profundidad y con clara intencionalidad de aplicación práctica. En su interior, plantea las bases conceptuales y metodológicas para enfrentarse a una 
gran cantidad de situaciones educativas en las que se hace necesario atender a la diversidad en los centros.

Comienza con la defensa de una educación y un currículum comprensivos, ambos necesarios para permitir el desarrollo de las competencias de cada uno de los estudiantes. En el segundo capítulo se abordan Estrategias para atender a la diversidad, a saber, el conocimiento de la realidad socioeducativa de todo el alumnado, la comprensión de los más diversos, las medidas para atender a la diversidad presentada y, por último, cómo realizar un posible plan de atención a la diversidad. En los capítulos tres, cuatro y cinco, se presentan las Medidas ordinarias para atender a la diversidad, las medidas extraordinarias y las medidas para atender a la diversidad en otros contextos. Como colofón, el último capítulo presenta un compendio de Materiales de ayuda para atender a la diversidad. En este capítulo se exponen un total de 36 recursos entre los que se encuentran diversos cuestionarios que facilitan la comprensión del contexto escolar, del alumnado y de los estilos de aprendizaje; esquemas de documentos educativos necesarios en la labor docente (Proyecto Curricular de Centro, Plan de Atención a la Diversidad, Plan de actividades de Orientación, Plan de Refuerzo educativo, etc.); plantillas de seguimiento en la adquisición de competencias; y varios ejemplos de rúbricas para determinar contenidos, habilidades, actitudes, valores, estrategias de aprendizaje, etc.
Podría parecer que el libro está descompensado al tener cinco capítulos dedicados al asiento de conceptos y comprensión del abordaje de la atención a la diversidad; sin embargo, es todo lo contrario, ya que ese soporte teórico no ocupa ni la mitad de la extensión del documento. Por lo tanto, el profesional de la enseñanza que necesite un recurso para usar con su alumnado, en su centro y/o con su grupo clase, dispone de una gran cantidad de herramientas y recursos modelo, que puede adaptar a su realidad, en el resto del documento.

Los coordinadores de este libro, María Julia Rubio Roldán, Ana María Martín Cuadrado y Jesús Cabrerizo Diago, todos docentes de la Universidad Nacional de Educación a Distancia, presentan un material de trabajo práctico de alta calidad, organizado y secuenciado tal y como lo necesita un docente hoy en día.

Estamos ante una obra pertinente y muy adecuada que puede servir de libro de cabecera para todos los profesionales - docentes y gestores-, que pueden tomar decisiones en el aula y así mejorar los soportes de atención a la diversidad en el ámbito formativo a cualquier nivel educativo. Recomendada para docentes en formación y para docentes en ejercicio, ya que estos últimos tendrán una fuente de recursos con los que comparar su actuación y mejorar la práctica diaria.

\section{Begoña Mora Jaureguialde Universidad Nacional de Educación a Distancia}

